\title{
BMJ Open Migration to the Downtown Eastside neighbourhood of Vancouver and changes in service use in a cohort of mentally ill homeless adults: a 10-year retrospective study
}

\author{
Julian M Somers, Akm Moniruzzaman, Stefanie N Rezansoff
}

To cite: Somers JM, Moniruzzaman A, Rezansoff SN. Migration to the Downtown Eastside neighbourhood of Vancouver and changes in service use in a cohort of mentally ill homeless adults: a 10-year retrospective study. BMJ Open 2016;6:e009043. doi:10.1136/bmjopen-2015009043

\section{- Prepublication history} and additional material is available. To view please visit the journal (http://dx.doi.org/ 10.1136/bmjopen-2015009043).

Received 11 June 2015 Revised 31 August 2015 Accepted 20 October 2015

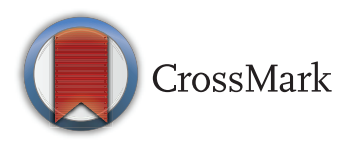

Faculty of Health Sciences, Simon Fraser University, Burnaby, British Columbia, Canada

Correspondence to Dr Julian M Somers; jsomers@sfu.ca

\section{ABSTRACT}

Objectives: Little research has investigated the role of migration as a potential contributor to the spatial concentration of homeless people with complex health and social needs. In addition, little is known

concerning the relationship between possible migration and changes in levels of service use over time. We hypothesised that homeless, mentally ill individuals living in a concentrated urban setting had migrated from elsewhere over a 10-year period, in association with significant increases in the use of public services.

Setting: Recruitment was concentrated in the Downtown Eastside neighbourhood of Vancouver, Canada.

Participants: Participants $(n=433)$ met criteria for chronic homelessness and serious mental illness, and provided consent to access administrative data.

Methods: Linked administrative data were used to retrospectively examine geographic relocation as well as rates of health, justice, and social welfare service utilisation in each of the 10 years prior to recruitment. Generalised estimating equations were used to estimate the effect of migration on service use.

Results: Over a 10-year period there was significant movement into Vancouver's Downtown Eastside neighbourhood (from $17 \%$ to $52 \%$ of the cohort). During the same period, there were significant annual increases in community medical services (adjusted rate ratio (ARR) per year=1.08; 95\% Cl 1.06 to 1.10), hospital admissions (ARR=1.08; 95\% Cl 1.04 to 1.11), criminal convictions (ARR=1.08; 95\% Cl 1.03 to 1.13 ), and financial assistance payments (ARR=1.04; 95\% Cl 1.03 to 1.06). Migration was significantly associated with financial assistance, but not with other types of services.

Conclusions: Significant increases in service use over a 10-year period coincided with significant migration into an urban area where relevant services were concentrated. These results highlight opportunities for early intervention in spatially diverse neighbourhoods to interrupt trajectories marked by worsening health and extremely high service involvement. Further research is urgently needed to investigate the causal relationships between physical migration, health and social welfare, and escalating use of public services.

\section{Strengths and limitations of this study}

- First investigation of geographic relocation among homeless mentally ill people over 10 years.

- Inclusion of comprehensive records of service use spanning health, justice and social welfare for each year studied.

- Demonstration that migration is associated with significant increases in service use.

- Cannot identify causal relationship between migration and service use.

- Limitations associated with use of administrative data (missing data, unmatched cases) apply.

Trial registration numbers: ISRCTN57595077 and ISRCTN66721740; Post-results.

\section{INTRODUCTION}

People who are chronically homeless are likely to have multiple health problems including mental illnesses, ${ }^{1}$ substance use disorders, ${ }^{2}$ and concurrent medical conditions. ${ }^{3}$ Health needs and social vulnerabilities among the homeless are associated with high rates of hospital service use ${ }^{4}$ as well as justice system contact. ${ }^{5}$ The associated pressure on urban authorities has led to responses that include large-scale programmes for rehousing $^{67}$ as well as police practices intended to disperse the members of this subpopulation. ${ }^{8}$

The prevalence of mentally ill and homeless individuals has been attributed in part to the closure of long-stay psychiatric hospitals, ${ }^{9}$ and their concentration in specific neighbourhoods has been linked to the geographic concentration of services for the homeless. ${ }^{10}$ Despite the intuitive logic of these explanations, little direct empirical evidence attests to 
the strength of their respective contributions to the phenomenon of visible street homelessness.

Previous research has found that housed people with mental illnesses migrate to locations where they have received care, ${ }^{11}$ and that those with serious mental illnesses change their location more frequently than either people with serious physical illnesses or people without a medical condition. ${ }^{12}$ Migration has also been shown to be a factor contributing to concentrations of homeless individuals in multiple urban centres including Sao Paolo, ${ }^{13}$ Osaka, ${ }^{14}$ Philadelphia and New York. $^{15}$ Importantly, few if any studies have examined geographic migration or service use patterns preceding the spatial concentration of people who are both homeless and mentally ill. It is therefore unclear whether the members of this subpopulation tend to be drawn from the local region or whether they migrate from further afield. Moreover, little is known about the long-term course of service use among those who experience prolonged homelessness and mental illness, and whether geographic relocation is associated with increases in service use. One of the most influential and widely implemented approaches to supporting homeless mentally ill adultsHousing First-provides clients with choices of housing in dispersed neighbourhoods. ${ }^{6}$ It is unknown however whether greater investment in community-based services (including supported housing) has the potential to prevent migration into homelessness in the first place. If so, this could justify the reallocation of resources from neighbourhoods with high concentrations of homelessness to other communities where problems leading to homelessness may originate. Research is needed to help inform these crucial questions and develop their implications for health resource planning as well as health promotion.

The present study investigated migration and levels of service use among people who were recruited on the basis of current homelessness and serious mental illness. Participants were enrolled in the Vancouver At Home (VAH) project, an experimental investigation of Housing First. ${ }^{2}$ Recruitment was conducted through extensive community consultation and with diverse collaborators (shelters, police, outreach teams, etc) in and around Vancouver's Downtown Eastside (DTES). The DTES neighbourhood includes the highest concentration of visible homelessness and related services in the city of Vancouver. The current study involved the analysis of data from administrative sources collected prior to randomisation and the implementation of interventions.

Previous research has shown that participants in VAH identified the DTES as the primary neighbourhood where they slept and spent time during the day. ${ }^{16}$ To date, several publications have described outcomes following randomisation in VAH, including impacts on residential stability, ${ }^{17}$ quality of life, ${ }^{18}$ emergency room visits, ${ }^{19}$ substance use ${ }^{20}$ and criminal offending. ${ }^{21}$ The present study examined the locations where participants received health, justice and social welfare services over the 10 years prior to study recruitment, and the volumes of each service in each year. Within the domain of health services we examined separately: discharges from the region's tertiary psychiatric hospital; and community medical services for psychiatric and non-psychiatric conditions. This is the first long-term retrospective analysis of the cohort, and the first study we are aware of describing the relationship between place and interagency service use in a sample of homeless and seriously mentally ill individuals. Data used in this study were derived from administrative sources over a decade prior to the interventions introduced by VAH. We hypothesised that there would be evidence of substantial migration into the DTES over 10 years, and evidence that rates of service use had increased in tandem with migration (ie, higher rates of service involvement in the DTES). Since local deinstitutionalisation was relatively complete 10 years prior to establishing this cohort, ${ }^{22}$ we hypothesised that few participants would have been discharged from the regional tertiary psychiatric hospital in the period of observation.

\section{METHODS}

\section{Ethics statement}

This study sample was recruited for two experimental trials: ISRCTN57595077 (Vancouver at Home study: Housing First plus Assertive Community Treatment vs congregate housing plus supports vs treatment as usual); and ISRCTN66721740 (Vancouver At Home study: Housing First plus Intensive Case Management vs treatment as usual)). The study protocols and research designs include planned analyses of administrative data ${ }^{2}$ during the years prior to recruitment in order to generate knowledge related to the pattern and course of service use prior to the advent of experimental interventions. All variables included were collected pre-randomisation.

\section{Recruitment and eligibility}

Participants were recruited with the assistance of service providers and agencies serving individuals who are homeless and mentally ill in Vancouver, including shelters, drop-in centers, street outreach workers, hospitals, police and courts. Community partners were briefed on inclusion criteria and directed interested individuals for screening by research staff. Eligible participants were Canadian citizens at least 19 years of age who met criteria for homelessness or precarious housing and current mental disorder status. Homelessness was defined as having no fixed place to sleep or live for more than seven nights and little likelihood of obtaining accommodation in the coming month. Precarious housing was defined as currently residing in marginal accommodation, such as a single room occupancy hotel, and having two or more episodes of homelessness (as defined above) during the past 12 months. These were minimal criteria, and participants with more long- 
standing homelessness were eligible for inclusion. Current mental illness was assessed using the Mini-International Neuropsychiatric Interview (MINI) ${ }^{23}$ for the following: major depressive episode, manic or hypomanic episode, post-traumatic stress disorder, mood disorder with psychotic features,and psychotic disorder. Where possible, mental disorder status was corroborated by physician diagnosis.

\section{Instruments and measures}

Data examined in the present study were drawn from the Baseline inventory of questionnaires administered to participants in the VAH study, including diagnostic information based on the MINI, ${ }^{23}$ substance-related details via the Maudsley Addiction Profile, ${ }^{24}$ and sociodemographic information. Separate consent was requested to enable researchers to receive administrative data records related to health, social service and criminal justice encounters. Details concerning historical health service involvement were provided by the Provincial Ministry of Health for consenting individuals (all British Columbia (BC) citizens are required to enrol in the Provincial Medical Services Plan (MSP), which entails the recording of a location code in each year of registration). Details of service use were provided by government departments responsible for health, justice and social welfare within the province. A full description of the VAH protocol, measures and study design has been published separately. ${ }^{2}$ No additional data are available.

\section{Analysis plan}

We used descriptive statistics (means and SDs for continuous variables; frequencies and percentages for categorical variables) to characterise the entire recruited sample and sample eligible for inclusion in the current analyses (ie, consent obtained, linkable data). We used independent sample $\mathrm{t}$ tests to compare numerical variables (such as age at randomisation and homeless duration) and Pearson's $\chi^{2}$ tests to compare categorical data (such as gender and ethnicity) between eligible and non-eligible participants. Self-report was used to obtain ethnicity, including whether participants identified as being Aboriginal.

We analysed administrative data for eligible participants over a period of 10 consecutive fiscal years prior to study recruitment. First, we examined the location of each participant over the 10 years before recruitment. Local health areas (LHAs, see online supplementary appendix A) represent neighbourhood-level data. In the province of $\mathrm{BC}$, there are 89 LHAs representing adult populations (over 19 years of age) ranging from 420 to over 300000 people. There are six LHAs in the city of Vancouver and a seventh category for people who are registered in the city but with no known address, comprised of those who are homeless. In order to examine migration between LHAs, we categorised these neighbourhoods into three groups: DTES, other Vancouver LHAs and all other Provincial LHAs. The majority of people who are registered as living in Vancouver but with no known address are located in the DTES, where meal and shelter resources are concentrated. ${ }^{25}$ Therefore, the response 'Vancouver unknown place' was allocated to the DTES and analyses were repeated without these data to test for potential differences in results. Details regarding the profile of LHAs have been reported elsewhere. ${ }^{26}$ As a descriptive analysis, we conducted multinomial logistic regression ${ }^{\mathrm{i}}$ to investigate the frequency of migration to the DTES and elsewhere in Vancouver compared with other more distant locations.

We selected the generalised estimating equations (GEE) method for the primary analysis, due to the longitudinal and count nature of our outcome variables. $^{27-29}$ Our outcome variable was involvement with health, social and justice services measured at each fiscal year during the observation period. We used the number of community medical encounters (MSP) and hospitalisations as indicators of health service involvement; number of social assistance payments as an indicator of social support; and number of convictions as an indicator of justice involvement. Social assistance payments are issued each month, and the number of payments issued per year indicates the degree of continuous need for support. Our primary independent variable was residing in LHAs of BC (categorised into three groups: Downtown Eastside, other LHA of Vancouver and other LHAs of BC) measured at each fiscal year during the same observation period. For the GEE analysis, we selected negative binomial models (NBR; negative binomial distribution with log link) due to the over-dispersion and count nature of the outcome data, and for better goodness of fit statistics relative to Poisson regression. Autoregressive (first order) correlation structure and a robust method were chosen to control for dependency over time and to estimate SEs for the parameters, respectively.

We examined the effects of LHAs on outcome variables in bivariate and multivariable settings. We selected age (measured at each fiscal year), gender (male and female), ethnicity (white, Aboriginal and other), severe non-substance-related mental disorders (either schizophrenia or bipolar disorder) and severe substance-related mental disorders (either alcohol or drug dependence) as potential confounders in each multivariable model. Diagnostic codes to determine mental disorders using administrative data have been described elsewhere. ${ }^{30} 31$ We tested the interaction term between time and LHAs but did not include it in the final model due to nonsignificance $(p>0.05)$. We reported both unadjusted and adjusted rate ratios along with $95 \%$ CIs as a measure of association (effect sizes). We chose the conventional $\alpha$ level $(p<0.05)$ to report significance for the estimated parameters. All reported $\mathrm{p}$ values were two sided.

${ }^{\mathrm{i}}$ We used LHAs as a dependent variable, time as an independent variable and Subject ID as a cluster variable. 
Participants with missing responses (unknown LHAs) were excluded from the analysis. IBM SPSS Statistics was used to conduct these analyses. ${ }^{32}$

\section{RESULTS}

Administrative data were obtained for $87 \%$ of the total sample (ie, informed consent provided followed by successful data linkage). Sociodemographic characteristics of the eligible sample $(n=433)$ and entire sample $(n=497)$ are summarised in table 1, with no significant between-group differences on the 19 variables examined. Participants were an average of 41 years old at the time of recruitment, and first experienced homelessness nearly 11 years prior to recruitment at a mean age of 30 . Females comprised $26 \%$ of the sample, $54 \%$ self-identified as being of white ethnicity and $68 \%$ were single or never married. Participants had been homeless for an average of 58 months in total, and for 30 months continuously in their longest episode of homelessness. Schizophrenia, bipolar disorder, or mood disorder with psychotic features ('severe cluster') were assessed in $72 \%$ of the sample, $58 \%$ met criteria for substance dependence, $18 \%$ were assessed as being at high risk of suicide, $70 \%$ had three or more chronic medical conditions and $32 \%$ had blood-borne infectious diseases.
Migration between LHAs

In the year of their recruitment into the study ('Last' year), $52 \%$ of the sample registered their location as the DTES LHA, including those coded as Vancouver Unknown Place (see figure 1 and table 2). Ten years prior to recruitment only $17 \%$ of the sample were registered in the DTES. Over the same period of time the percentage of the sample registered in other parts of Vancouver was extremely stable (between 21 and 25\% overall years), while the percentage registered in other parts of BC decreased from $39 \%$ to $21 \%$. Those whose location was 'unknown' decreased from $20 \%$ to $3 \%$ over the 10 years observed. The multinomial regression analysis demonstrated an annual increase of $18 \%$ for DTES participants $(p<0.001)$ and a $6 \%$ increase $(p<0.001)$ for other Vancouver LHAs participants compared to other LHAs of BC.

\section{Service use over 10 years}

Over the 10 years prior to recruitment, participants' use of community medical services and hospital services each tripled, while criminal convictions and welfare receipt doubled (see table 3). In the year prior to recruitment ('Last' year) participants had over 50

Table 1 Sociodemographic characteristics of 'Vancouver At Home' participants by consent status at enrolment visit

\begin{tabular}{|c|c|c|c|c|}
\hline Variable & $\begin{array}{l}\text { Entire sample }(n=497) \\
n(\%) / \text { mean }(S D)\end{array}$ & $\begin{array}{l}\text { Eligible sample }{ }^{\star} \\
(n=433) n(\%) / \text { mean } \\
(\mathrm{SD})\end{array}$ & $\begin{array}{l}\text { Not eligible sample } \\
(n=64) n(\%) / \text { mean (SD) }\end{array}$ & P Valueł \\
\hline Age at randomisation (in years) & $40.8(11.0)$ & $40.8(11.0)$ & $41.4(11.0)$ & 0.682 \\
\hline Age of first homelessness (in years) & $30.3(13.3)$ & 30.1 (13.4) & $31.9(12.6)$ & 0.301 \\
\hline Female & $134(27)$ & $112(26)$ & $22(34)$ & 0.165 \\
\hline \multicolumn{5}{|l|}{ Ethnicity } \\
\hline Aboriginal & $77(16)$ & $70(16)$ & $7(11)$ & 0.054 \\
\hline White & $280(56)$ & $235(54)$ & $45(70)$ & \\
\hline Other & $140(28)$ & $128(30)$ & $12(19)$ & \\
\hline Incomplete high school & $280(57)$ & $247(57)$ & $33(52)$ & 0.376 \\
\hline Single/never married & $343(70)$ & $293(68)$ & $50(79)$ & 0.071 \\
\hline $\begin{array}{l}\text { Lifetime duration of homelessness } \\
\text { (in months) }\end{array}$ & $60.2(70.3)$ & $58.3(64.8)$ & $72.9(99.8)$ & 0.124 \\
\hline $\begin{array}{l}\text { Longest episode of homelessness } \\
\text { (in months) }\end{array}$ & $30.9(40.1)$ & 30.4 (39.5) & $34.1(44.4)$ & 0.498 \\
\hline $\begin{array}{l}\text { Less severe cluster of mental } \\
\text { disorders }\end{array}$ & $264(53)$ & $235(54)$ & $29(45)$ & 0.180 \\
\hline Severe cluster of mental disorders $\S$ & $363(73)$ & $311(72)$ & $52(81)$ & 0.113 \\
\hline Suicidality (high) & $87(17)$ & 79 (18) & $8(12)$ & 0.259 \\
\hline Substance dependence & $288(58)$ & $252(58)$ & $36(56)$ & 0.768 \\
\hline Daily substance use & $143(29)$ & $131(30)$ & 12 (19) & 0.064 \\
\hline $\begin{array}{l}\text { Mental health severity/CSI score } \\
\text { (per unit) }\end{array}$ & $37.2(12.5)$ & $37.4(12.5)$ & $35.8(12.9)$ & 0.371 \\
\hline $\begin{array}{l}\text { Chronic medical conditions } \\
\text { (3 or more) }\end{array}$ & $344(69)$ & $305(70)$ & $39(61)$ & 0.124 \\
\hline $\begin{array}{l}\text { Blood-borne infectious disease } \\
\text { (HIV, hepatitis B or C) }\end{array}$ & $157(32)$ & $139(32)$ & $18(29)$ & 0.603 \\
\hline
\end{tabular}




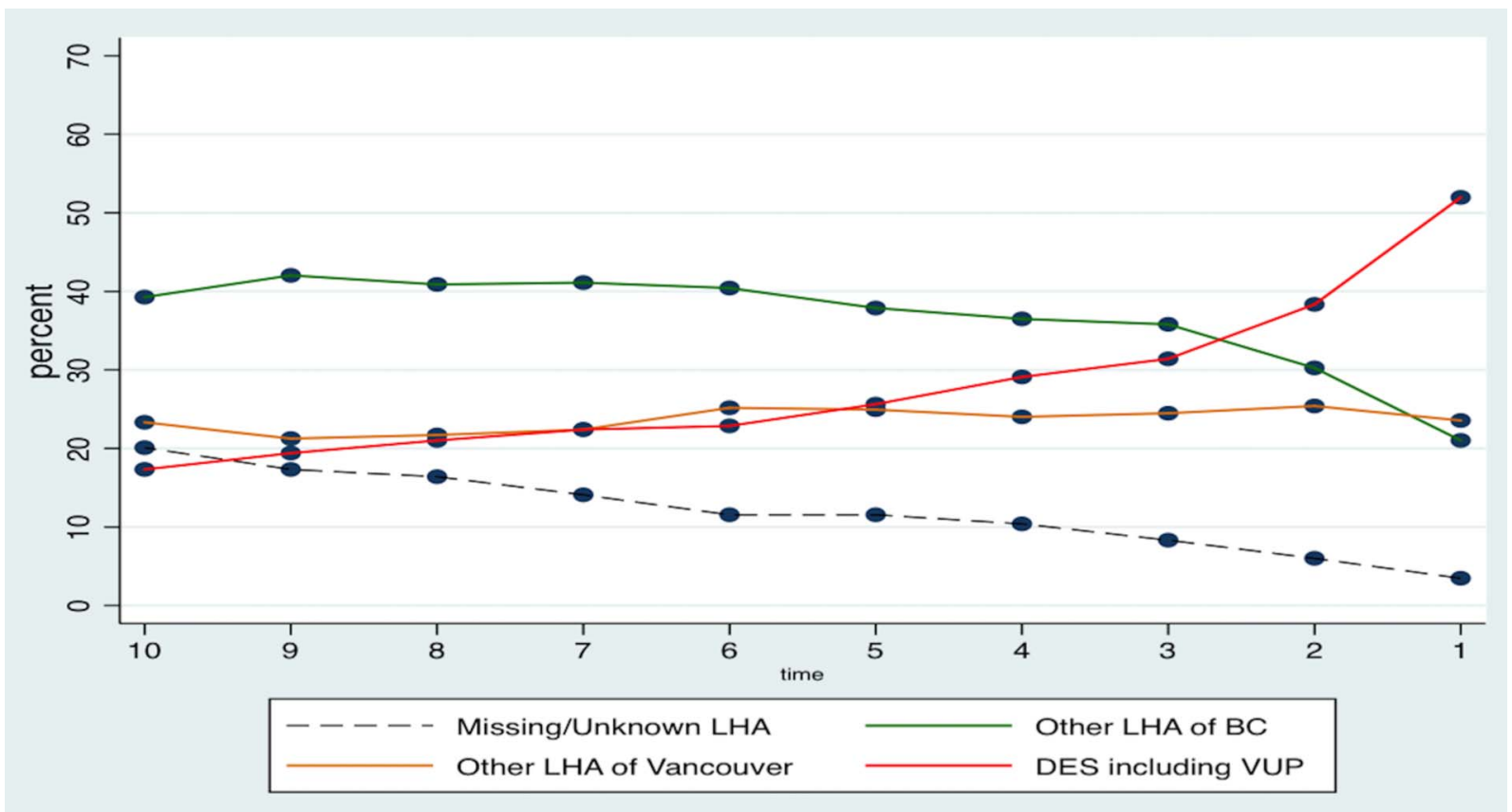

Figure 1 Annual distribution of participants between LHA. BC, British Columbia; LHA, local health area; DTES, Downtown Eastside; VUP, Vancouver Unknown Place.

community medical services, of which the majority (34.7) were for non-psychiatric reasons. In the same year participants spent, on average, nearly 12 days in hospital, received nine income assistance payments (issued monthly, to a maximum of 12 payments per year), and had one criminal conviction. We examined records from the regional tertiary psychiatric hospital (results not tabulated) and found that members of the cohort were discharged 53 times over the 10 years observed.

Results of GEE indicate significant increases in each domain of service. Adjusted rate ratios (ARR) and 95\% CIs $(95 \%$ CI) are presented in table 4 . There were significant annual increases in community medical services $(\mathrm{ARR}=1.08$; $95 \%$ CI 1.06 to 1.10 ), hospital admissions (ARR $=1.08 ; 95 \%$ CI 1.04 to 1.11 ), income assistance (ARR $=1.08$; 95\% CI 1.03 to 1.13 ) and criminal convictions (ARR $=1.04 ; 95 \%$ CI 1.03 to 1.06$)$. The rate of financial assistance receipt increased significantly more in the
DTES (ARR $=1.12 ; 95 \%$ CI 1.05 to 1.18 ) and Vancouver (ARR $=1.10 ; 95 \%$ CI 1.03 to 1.17 ) compared to other parts of the province. The rate of criminal convictions was significantly lower in 'other LHAs of Vancouver' (ie, excluding the DTES) compared to other parts of the province (ARR $=0.71 ; 95 \%$ CI 0.51 to 0.97 ). For other service categories the rate of increase did not differ significantly between the geographic units examined.

A sensitivity analysis was conducted excluding those whose location was Vancouver Unknown Place and results were consistent with the previous model (see online supplementary table SA1).

\section{DISCUSSION}

Our findings indicate that people experiencing longstanding homelessness and serious psychiatric comorbidities in Vancouver's DTES had overwhelmingly moved

Table 2 Distribution of LHA by fiscal year over a decade (from previous year to 10th last year) for 'Vancouver At Home' participants $(n=433)$

\begin{tabular}{lllllllllll} 
LHA & Last & 2nd Last & 3rd Last & 4th Last & 5th Last & 6th last & 7th last & 8th last & 9th last & 10th last \\
\hline $\begin{array}{l}\text { Downtown } \\
\text { Eastside (DTES)* }\end{array}$ & $225(52)$ & $166(38)$ & $136(31)$ & $126(29)$ & $111(26)$ & $99(23)$ & $97(22)$ & $91(21)$ & $84(19)$ & $75(17)$ \\
$\begin{array}{l}\text { Other LHA of } \\
\text { Vancouvert }\end{array}$ & $102(24)$ & $110(25)$ & $106(24)$ & $104(24)$ & $108(25)$ & $109(25)$ & $97(22)$ & $94(22)$ & $92(21)$ & $101(23)$ \\
Other LHA of BC & $91(21)$ & $131(30)$ & $155(36)$ & $158(36)$ & $164(38)$ & $175(40)$ & $178(41)$ & $177(41)$ & $182(42)$ & $170(39)$ \\
Unknown & $15(3)$ & $26(6)$ & $36(8)$ & $45(10)$ & $50(12)$ & $50(12)$ & $61(14)$ & $71(16)$ & $75(17)$ & $87(20)$ \\
\hline
\end{tabular}

*Includes Vancouver Unknown Place (VUP).

†Includes all LHA of Vancouver Heath Services Delivery Area (HSDA) except Downtown East Side (DTES) \& Vancouver Unknown Place (VUP).

BC, British Columbia; LHA, local health area. 


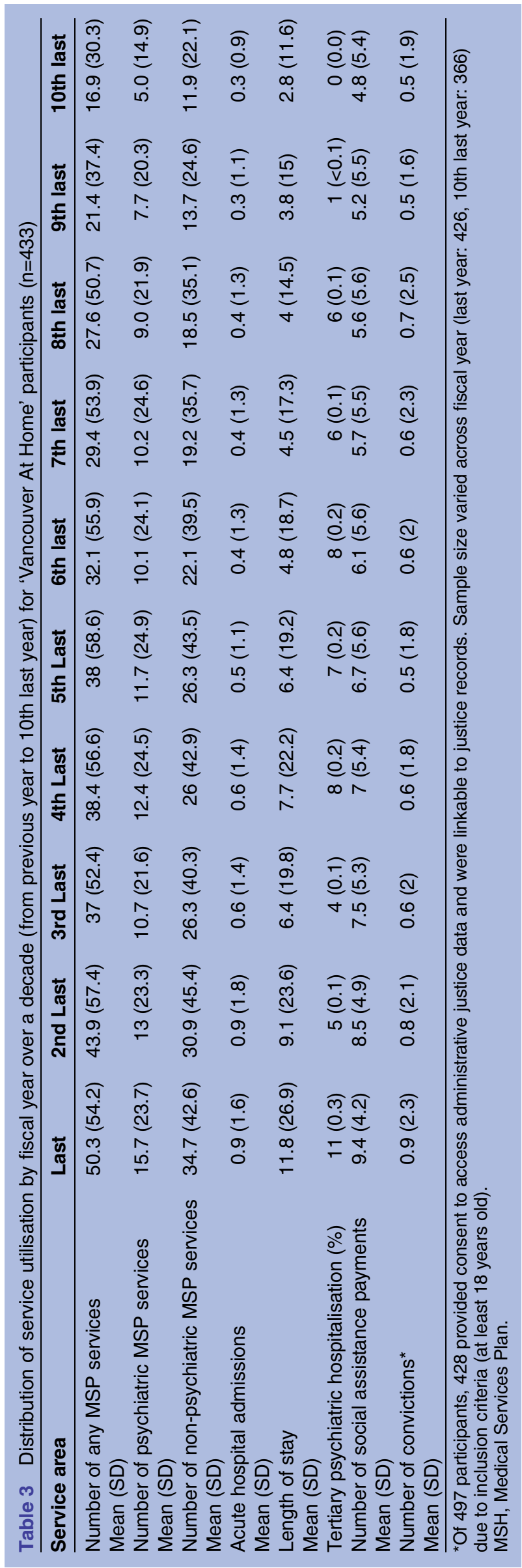

into the neighbourhood from other places over a period of 10 years preceding their current status. Our results are consistent with the hypothesis that members of this subpopulation migrate to areas with high concentrations of services. During the same period of time participants' involvement with health, justice and social assistance increased significantly, reflecting the mounting complexity of health and social needs within the cohort. Social assistance payments increased at a significantly greater rate among those in the DTES than in other regions. The rate of increase in hospitalisations, community medical treatments and criminal convictions did not differ significantly between regions. This is the first study to examine long-term changes in service use alongside geographic migration in a sample of chronically homeless mentally ill adults.

Participants became homeless 11 years prior to recruitment, and had been street homeless for a cumulative period of roughly 5 years. In the year prior to recruitment, participants received an average of 50 community medical services and spent 12 days in hospital. They also had roughly one criminal conviction per person, and received income assistance payments in 9 out of 12 possible months. All participants were mentally ill with the majority $(72 \%)$ having been diagnosed with schizophrenia, mood disorder with psychotic features or bipolar disorder in addition to substance dependence (58\%). Despite prevalent mental health needs, the majority of medical encounters were associated with non-psychiatric conditions. Nearly one-third of the sample $(32 \%)$ had blood-borne infectious diseases and a majority (70\%) had three or more chronic medical conditions (eg, asthma, diabetes and arthritis). Members of the cohort $(n=433)$ were discharged from the region's tertiary psychiatric facility 53 times in the 10 years observed, suggesting that deinstitutionalisation was not a major direct contributor to homelessness within our sample.

The DTES is home to a high concentration of resources for the homeless such as shelters, food, low rent accommodations, street nurses and drop-in health facilities. ${ }^{33}$ However, it is also an area rife with problems including substance use ${ }^{34}$ crime,$^{35}$ sexually transmitted infections ${ }^{36}$ and poverty. ${ }^{37}$ Features of the environment, such as single room occupancy hotels, have been shown to be associated with poor health status and disease risk. ${ }^{38}$ The high prevalence of multimorbidities in the current sample coincides with their exposure to highrisk settings.

Despite the high concentration of services and supports in the DTES, members of the current sample experienced significant personal decline rather than recovery, as evidenced by their involvements with criminal justice, large increases in acute care and prolonged homelessness. Ten years prior to their recruitment, only $17 \%$ of participants were located in the DTES and $23 \%$ were in other parts of Vancouver. The remainder were in other parts of the province $(39 \%)$ or had unknown status $(20 \%)$, which would include people residing 
Table 4 GEE regression analysis to estimate the effect of migration between LHAs on service utilisation for 'Vancouver At Home' participants $(n=433)$

\begin{tabular}{|c|c|c|c|c|c|}
\hline $\begin{array}{l}\text { Outcome variable-service } \\
\text { utilisation across public } \\
\text { service domains }\end{array}$ & $\begin{array}{l}\text { Independent variable-local } \\
\text { health areas }\end{array}$ & $\begin{array}{l}\text { Unadjusted rate } \\
\text { ratio }(95 \% \mathrm{Cl}) \\
\end{array}$ & p Value & $\begin{array}{l}\text { Adjusted rate ratio* } \\
(95 \% \mathrm{Cl})\end{array}$ & p Value \\
\hline \multirow[t]{4}{*}{ Number of any MSP services } & Downtown Eastside (DTES)† & $1.12(0.98$ to 1.27$)$ & 0.092 & $1.02(0.89$ to 1.17$)$ & 0.781 \\
\hline & Other LHA of Vancouver & $1.09(0.96$ to 1.23$)$ & 0.199 & $1.05(0.89$ to 1.25$)$ & 0.563 \\
\hline & Other LHA of BC & Reference & - & Reference & \\
\hline & Time (per fiscal year) & $1.12(1.11$ to 1.14$)$ & $<0.001$ & $1.08(1.06$ to 1.10$)$ & $<0.001$ \\
\hline \multirow{4}{*}{$\begin{array}{l}\text { Number of acute hospital } \\
\text { admissions }\end{array}$} & Downtown Eastside (DTES) & $1.06(0.84$ to 1.34$)$ & 0.605 & 0.91 (0.74 to 1.13$)$ & 0.412 \\
\hline & Other LHA of Vancouver & 0.85 (0.67 to 1.09$)$ & 0.192 & $0.75(0.59$ to 0.96$)$ & 0.020 \\
\hline & Other LHA of BC & Reference & - & Reference & \\
\hline & Time (per fiscal year) & $1.14(1.10$ to 1.18$)$ & $<0.001$ & $1.08(1.04$ to 1.11$)$ & $<0.001$ \\
\hline \multirow{4}{*}{$\begin{array}{l}\text { Number of social assistance } \\
\text { payments }\end{array}$} & Downtown Eastside (DTES) & $1.14(1.08$ to 1.20$)$ & $<0.001$ & 1.12 (1.05 to 1.18$)$ & $<0.001$ \\
\hline & Other LHA of Vancouver & 1.09 (1.02 to 1.16$)$ & 0.007 & $1.10(1.03$ to 1.17$)$ & 0.006 \\
\hline & Other LHA of BC & Reference & - & Reference & \\
\hline & Time (per fiscal year) & $1.08(1.07$ to 1.09$)$ & $<0.001$ & $1.04(1.03$ to 1.06$)$ & $<0.001$ \\
\hline \multirow[t]{4}{*}{ Number of convictions } & Downtown Eastside (DTES) & 1.15 (0.84 to 1.57$)$ & 0.384 & 1.18 (0.83 to 1.68$)$ & 0.353 \\
\hline & Other LHA of Vancouver & $0.76(0.55$ to 1.03$)$ & 0.076 & $0.71(0.51$ to 0.97$)$ & 0.033 \\
\hline & Other LHA of BC & Reference & & Reference & \\
\hline & Time (per fiscal year) & $1.07(1.03$ to 1.11$)$ & 0.002 & $1.08(1.03$ to 1.13$)$ & 0.002 \\
\hline
\end{tabular}

outside $\mathrm{BC}$ and therefore not enrolled in the province's mandatory health insurance programme. Over the subsequent 10 years the percentage of the sample in the DTES increased to $52 \%$, with commensurate reductions in the percentage outside Vancouver (21\%) and among those whose status was unknown $(3 \%)$. The percentage in Vancouver (outside DTES) remained stable over time $(21 \%)$, indicating that migration was primarily associated with people relocating from outside the city.

Financial assistance involvement increased at a greater rate in the DTES and Vancouver than elsewhere in BC, perhaps reflecting the greater concentration of service providers and advocates in the urban environment to ensure that eligible people receive assistance. Rates of contact with other providers (hospital, medical and justice) did not increase differentially between regions, which may be due to the fact that these services are reactive to extreme or urgent circumstances and are deployed relatively consistently across geographic boundaries.

These results suggest that our sample of homeless and mentally ill individuals experienced long-term deterioration in health and social welfare despite significantly increased rates of public service use. Migration into urban regions with high concentrations of services may not lead to effective pathways to recovery, while exposing individuals to health and social risks associated with poverty. ${ }^{34-37}$ Members of the current cohort first experienced homelessness on average 11 years prior to recruitment, and prior to the observed process of migration. It is unclear whether the implementation of housing and support services adapted for rural settings ${ }^{39} 40$ could prevent the extreme morbidity, personal hardship and escalating rates of service use reported in this study. Further research is needed to replicate our findings and examine opportunities for early intervention.

Several limitations of this study relate to our use of administrative data, including potentially incomplete information, classification and coding errors, and the fact that $13 \%$ of the sample either did not provide consent or could not be linked to relevant data. Health registry data are an excellent source of information concerning the location in which individuals receive care. However, they may not indicate the location where homeless individuals are residing at night and therefore restrict inferences concerning environmental exposure and related risks. The correlational nature of our analysis does not address the causal relationships between migration, service availability and service use. Strengths of this study are the large sample of individuals meeting criteria for homelessness and mental illness, diverse sources of comprehensive service use and a 10-year period of analysis.

Our findings illustrate a long-term process of worsening personal and public health, decreases in personal and public safety, and large increases in the use of public resources. While many people may be well served by existing resources for the homeless, including those that are concentrated in urban settings, ${ }^{41}$ the current study focuses on the subset who are inadequately supported. People who are chronically homeless and mentally ill are at risk for premature mortality ${ }^{4-44}$ and 
becoming trapped in a costly 'revolving door' involving healthcare, the justice system and the street. ${ }^{45}$ Interventions to prevent chronic homelessness are crucial. The current research suggests that the geographic focus for these efforts may be distant from the places where street homelessness, mental illness and substance use are most visible.

Contributors JMS led the overall study and drafted the complete manuscript. AM contributed to the analytic design and conducted the statistical analyses. SNR contributed to the design of the study and wrote sections of the manuscript. All authors read and approved the manuscript for submission.

\section{Competing interests None declared.}

Funding This research was supported by a grant provided by the Mental Health Commission of Canada.

Patient consent Obtained.

Ethics approval Office of Research Ethics, Simon Fraser University and the appropriate research and privacy committees of the Government of British Columbia.

Provenance and peer review Not commissioned; externally peer reviewed.

Data sharing statement Data related to this study are available via the corresponding author

Open Access This is an Open Access article distributed in accordance with the Creative Commons Attribution Non Commercial (CC BY-NC 4.0) license which permits others to distribute, remix, adapt, build upon this work noncommercially, and license their derivative works on different terms, provided the original work is properly cited and the use is non-commercial. See: http:// creativecommons.org/licenses/by-nc/4.0/

\section{REFERENCES}

1. Fazel S, Khosla V, Doll H, et al. The prevalence of mental disorders among the homeless in western countries: systematic review and meta-regression analysis. PLoS Med 2008;5:e225.

2. Somers JM, Patterson ML, Moniruzzaman A, et al. Vancouver At Home: pragmatic randomized trials investigating housing first for people who are homeless and mentally ill adults. Trials 2013;14:365.

3. Hwang SW. Homelessness and health. Cdn Med Assn J 2001;164:229-33.

4. Kushel MB, Perry S, Bangsberg D, et al. Emergency department use among the homeless and marginally housed: results from a community-based study. Am J Public Health 2002;92:778-84.

5. Constantine R, Andel R, Petrila J, et al. Characteristics and experiences of adults with a serious mental illness who were involved in the criminal justice system. Psychiatr Serv 2010;61:451-7.

6. Tsemberis S, Gulcur L, Nakae M. Housing First, consumer choice, and harm reduction for homeless individuals with a dual diagnosis. Am J Public Health 2004:94:651-6.

7. Rickards LD, McGraw SA, Araki L, et al. Collaborative initiative to help end chronic homelessness: introduction. J Behav Health Serv Res 2010;37:149-66.

8. Berk R, MacDonald J. Policing the homeless. Criminol Public Policy 2010;9:813-40.

9. Lamb HR, Bachrach LL. Some perspectives on deinstitutionalization Psychiatr Serv 2001;52:1039-45.

10. Culhane DP. Tackling homelessness in Los Angeles' skid row. Criminol Public Policy 2010;9:851-7.

11. Lamont A, Ukoumunne OC, Tyrer $\mathrm{P}$, et al. The geographical mobility of severely mentally ill residents in London. Soc Psychiatry Psychiatr Epidemiol 2000;35:164-9.

12. Lix LM, Hinds A, DeVerteuil G, et al. Residential mobility and severe mental illness: a population-based analysis. Adm Policy Ment Health 2006;33:160-71.

13. Schor SM, Artes R, Bomfim VC. Determinants of spatial distribution of street people in the city of São Paulo. Urban Aff Rev 2003;38:592-602

14. Iwata S, Karato K. Homeless networks and geographic concentration: evidence from Osaka city. Pap Reg Sci 2011;90:27-46.
15. Culhane DP, Lee CM, Wachter SM. Where the homeless come from: a study of the prior address distribution of families admitted to public shelters in New York City and Philadelphia. Housing Policy Debate 1996;7:327-65.

16. Patterson M, Markey M, Eiboff F. Baseline personal story interviews from the Vancouver at home study. Mental Health Commission of Canada, 2011.

17. Palepu A, Patterson ML, Moniruzzaman A, et al. Housing First improves residential stability for homeless Adults with Concurrent Substance Dependence and Mental Disorders. Am J Public Health 2013;103(Suppl 2):e30-6

18. Patterson M, Moniruzzaman A, Palepu A, et al. Housing First improves Subjective quality of life among formerly homeless adults with mental illness: a randomized controlled trial in Vancouver, British Columbia. Soc Psychiatry Psychiatr Epidemiol 2013;48:1245-59.

19. Russolillo A, Patterson M, McCandless L, et al. Emergency department utilisation among formerly homeless adults with menta disorders after one year of Housing First interventions: a randomised controlled trial. Int J Housing Policy 2014;14:79-97.

20. Somers JM, Moniruzzaman A, Palepu A. Changes in daily substance use among people experiencing homelessness and mental illness: 24-month outcomes following randomization to Housing First or usual care. Addiction 2015;110:1605-14.

21. Somers JM, Rezansoff S, Moniruzzaman A, et al. Housing First reduces re-offending among formerly homeless adults with mental disorders: results of a randomized controlled trial. PLOS ONE 2013;8:1-8.

22. Livingston JD, Nicholls T, Brink J. The impact of realigning a tertiary psychiatric hospital in British Columbia on other institutional sectors. Psychiatr Serv 2014;62:200-5.

23. Sheehan DV, Lecrubier $\mathrm{Y}$, Sheehan $\mathrm{KH}$, et al. The Mini-International Neuropsychiatric Interview (MINI): the development and validation of a structured diagnostic psychiatric interview for DSM-IV and ICD-10. J Clin Psychiatry 1998;59:20-33.

24. Marsden J, Gossop M, Stewart D, et al. The Maudsley Addiction Profile (MAP): a brief instrument for assessing treatment outcome. Addiction 1998;93:1857-67.

25. Greater Vancouver Regional Steering Committee on Homelessness. Results of the 2014 homeless count in metro Vancouver region. 2014.

26. Somers JM, Moniruzzaman A, Rezansoff SN, et al. The prevalence and geographic distribution of complex co-occurring disorders: a population study. Epidemiol Psychiatr Sci 2015;20:1-11.

27. Zeger SL, Liang KY. The analysis of discrete and continuous longitudinal data. Biometrics 1986;42:121-30.

28. Hubbard AE, Ahern J, Fleischer NL, et al. To GEE or not to GEE: comparing population average and mixed models for estimating the associations between neighborhood risk factors and health. Epidemiology 2010;21:467-74

29. Hanley JA, Negassa A, Edwardes MD, et al. Statistical analysis of correlated data using generalized estimating equations: an orientation. Am J Epidemiol 2003;157:364-375.

30. Rezansoff SN, Moniruzzaman A, Gress C, et al. Psychiatric diagnoses and multiyear criminal recidivism in a Canadian provincial offender population. Psychol Public Policy Law 2013;19:443-53.

31. Somers JM, Currie L, Moniruzzaman A, et al. Drug treatment court of Vancouver: $\mathrm{n}$ empirical evaluation of recidivism. Int J Drug Policy 2012;23:393-400.

32. IBM Corp. IBM SPSS statistics for Windows, Version 22.0. Armonk, NY: IBM Corp, 2013.

33. Culbert L, Boyd N, Campbell L. A thousand dreams: Vancouver's downtown eastside and the fight of its future. Vancouver: D\&M, 2010.

34. MacPherson D, Mulla Z, Richardson L. The evolution of drug policy in Vancouver, Canada: strategies for preventing harm from psychoactive substance use. Int J Drug Policy 2010;17:127-32.

35. Andresen MA. A spatial analysis of crime in Vancouver, British Columbia: a synthesis of social disorganization and routine activity theory. Can Geographer 2006;50:487-502.

36. Kuyper LM, Collins CL, Kerr T, et al. The prevalence and incidence of sexually transmitted infections in a prospective cohort of injection drug users in Vancouver, British Columbia. Can J Infect Dis Med Microbiol 2005;16:225-9.

37. Burnett K. Commodifying poverty: gentrification and consumption in Vancouver's Downtown Eastside. Urban Geography 2013;5:157-76.

38. Shannon K, Ishida T, Lai C, et al. The impact of unregulated single room occupancy hotels on the health status of illicit drug users in Vancouver. Int J Drug Policy 2006;17:107-14.

39. Tsemberis S, Kent D, Respress C. Housing stability and recovery among chronically homeless persons with co-occurring disorders in Washington, DC. Am J Public Health 2012;102:13-16. 
40. Stefancic $\mathrm{A}$, Henwood BF, Melton $\mathrm{H}$, et al. Implementing housing first in rural areas: pathways Vermont. Am J Public Health 2013;103 (Suppl 2):S206-9.

41. Kuhn R, Culhane DP. Applying cluster analysis to test a typology of homelessness by pattern of shelter utilization: results from the analysis of administrative data. Am J Community Psychol 1998;26:207-32.

42. Martens WH. A review of physical and mental health in homeless persons. Public Health Rev 2001;29:13-33.
43. Weinstein LC, LaNoue MD, Plumb JD, et al. A primary care-public health partnership addressing homelessness, serious mental illness and health disparities. J Am Board Fam Med 2013;26:279-87.

44. Peate I. The other silent killer: homelessness. Br J Nurs 2013;22:607.

45. Baillargeon J, Binswanger IA, Penn JV, et al. Psychiatric disorders and repeat incarcerations: the revolving prison door. Am J Psychiatry 2009;166:103-9. 